\title{
Cell therapies: a new era in the battle against cancer
}

\author{
Diana Hernández and Alejandro Madrigal \\ Anthony Nolan, University College London, The Royal Free Hospital, London, United Kingdom
}

Cell therapy is the use of cells as therapeutic agents; therein, two large areas can be differentiated: one that involves regeneration, substitution or replacement of functional cells (therapy with stem cells) and another related to the use of immune cells, which seeks to exploit their capabilities as effectors or suppressors of the immune system (cell immunotherapy).

The use of hematopoietic progenitors is not new, it dates more than 50 years back and perhaps it is the most successful example of cell therapy thus far. Hematopoietic progenitor cell transplantation is carried out with curative purposes in leukemias or lymphomas; however, it is still a procedure with high mortality, since the patient requires high doses of chemotherapy or radiation previously in order to eliminate tumor cells, condition the spinal niche to house the graft and produce immunosuppression to avoid graft rejection. Nevertheless, hematopoietic transplant is relatively common: annually, 42000 procedures are carried out throughout the world and they are currently safer.

Another relevant advance is the manipulation of graft cells to improve the transplant. Two procedures stand out: the use of haploidentical grafts with T lymphocyte in vitro reduction prior to the transplant and stem cells ex vivo expansion. The latter has been specifically applied to umbilical cord blood, since it is the most limited source in terms of cell numbers. There are four products that have been clinically tested with positive responses:

- NiCord ${ }^{\circledR}$ by Gamida Cell (Israel) in phase III clinical trials. ${ }^{1,2}$

- MGTA-456 ${ }^{\circledR}$ by Magenta Therapeutics (United States) on phase I/II. 3,4

- UM171 (ECL101) from ExCellThera (Canada) on phase $\mathrm{I} / \mathrm{II} .5,6$

- NLA101 from Nohla Therapeutics (United States) on phase II., 7
The use of umbilical cord for hematopoietic progenitor cell transplantation was increased until 2016, since it was shown to be less likely to cause graft-versus-host disease (GVHD), even with lower HLA compatibility than necessary when adult cells are used and, additionally, it doesn't cause complications to the donor. However, mainly due to its high cost and to the delay in the establishment of the graft, it has been replaced over the past two years by haploidentical transplants. New studies have demonstrated that cell expansion is a safe and well tolerated procedure, and that the time required for the graft to establish is equal to that of adult cells, which makes this source of stem cells highly attractive.

On the other hand, treatments with immune cells have had a great boost over the last decade; these treatments use the natural ability of these cells to destroy pathogens and tumor cells. Therapeutic manipulation of the immune system can overcome the morbidity and mortality caused by a deficient adaptive immunity and by malignant tumors that are resistant to other therapeutic procedures, surgical radiotherapy or chemotherapy.

Interventions to modulate immune reactivity can be valuable to treat autoimmune and chronic inflammatory diseases, and the measures to provide adaptive, active or adoptive immunity are vital to reduce morbidity and mortality of patients and recipients.

The different modalities of organ, tissue and cell transplantation, as well as the effectiveness of hematopoietic stem cell transplantation to treat hematological malignancies can be potentiated by interventions aimed at providing adoptive or endogenously generated antitumor reactivity. The first clinical trials to investigate the ability of $T$ lymphocytes to detect and eliminate tumor cells used $T$ lymphocytes isolated from patient tumors and expanded in vitro. These cells were shown to have specificity against the tumor and, in some cases, they were efficacious in eliminating it. Unfortunately,
Correspondence:

Alejandro Madrigal

E-mail: a.madrigal@ucl.ac.uk
Date of reception: 13-09-2018

Date of acceptance: 20-09-2018

DOI://dx.doi.org/10.24875/GMM.M18000200
Gac Med Mex. 2018;154:462-464

Contents available at PubMed www.gacetamedicademexico.com 
isolation and expansion of clones is laborious and in most cases it turns out to be an extremely long procedure to be of clinical utility.

Perhaps the most important advance has been the use of the so-called chimeric antigen receiver $T$ cells (CAR-T cells). ${ }^{9}$ These cells, as their name implies, are effector T lymphocytes whose role is to recognize, attack and destroy cancer or infected cells. T lymphocytes recognize specific epitopes in affected cells and destroy them; this molecular recognition, mediated by the $T$ cell receptor in the context of class I HLA, can be manipulated using genetic engineering to create T-lymphocyte clones that express a transgenic chimeric receptor and identify, for example, the CD19 antigen located exclusively in B lymphocytes and, therefore, they can be used to treat patients with B-line lymphoproliferative syndromes, including chronic lymphocytic leukemia.

The Food and Drug Administration has approved two cell therapies composed of transgenic $T$ lymphocytes: Kymriah ${ }^{\circledR}$ from Novartis (Switzerland), ${ }^{10}$ for the treatment of pediatric B-cell acute lymphoblastic leukemia, and Yescarta ${ }^{\circledR}$ from Gilead (United States), ${ }_{11}^{11}$ for the treatment of non-Hodgkin lymphoma. Other companies and several academic groups, both in the United States and in Europe, have advanced clinical programs where similar products are used (e.g., Cellectis, Celyad, Juno and Bluebird Bio).

These cell therapies have the potential to revolutionize cancer treatment and have proved their effectiveness in patients that are resistant to other treatments, rapidly eradicating lymphomas or leukemias with high tumor burden. However, they have several problems: currently, they can only be used against leukemia or B-cell lymphomas, and can cause serious neurological complications and, especially, cytokine release syndrome, the prognosis of which is unfortunate. On the other hand, their cost is extremely high: one dose of Kymriah costs nearly 500000 US dollars. Nevertheless, this revolutionary modality against cancer is real and has driven the development of other immunotherapies, including the use of NK (natural killer) cells for the treatment in relapses and mesenchymal cells for the treatment of GVHD.

NKs are innate immune system cells specialized in recognizing and eliminating cells that have been transformed into tumor cells or suffered viral infection, without the need for prior recognition or sensitization, as it occurs with $\mathrm{T}$ lymphocytes; this property can be used for the treatment of hematological malignancies, but it is necessary for cells to be ex vivo cultured to expand them and potentiate their antitumor activity.

In recent years, several preclinical and clinical studies have demonstrated the feasibility of adaptively transferring NK cells. Clinical studies can be divided in two: those that combine them with hematopoietic progenitor transplantation, and those that only use NK cell transplantation. In the first group, safety of the procedures has been demonstrated in most patients, without reported toxicity; however, it has been difficult to prove their efficacy, since numerous patients developed GVHD, caused by T lymphocytes in the graft. All studies of NK cell transfer as single cell therapy were shown to be safe, and efficacy in terms of tumor burden reduction is apparent, at least in cases of hematological malignancies, but less obvious in solid tumors. ${ }^{12}$

Using genetic engineering, several groups have developed CAR-NK cells using vectors similar to those employed in the generation of CAR-T cells, whose target are cells that express CD19 (B lymphocytes). CAR-NKs attack these cells, but unlike T cells, they don't need to have HLA-compatible and, therefore, they do not cause GVHD, which allows NK cell products to be created from cells from a non- related donor (allogenic), by means of which production costs are substantially reduced. ${ }^{13}$

On the other hand, the usefulness of mesenchymal cells has been widely explored in the treatment of neoplasms and autoimmune conditions such as GVHD, lupus and multiple sclerosis. Their action has been established to be exerted by secreting cytokines and other molecules with pro- and anti-inflammatory, as well as regenerative capabilities, rather than by their ability to integrate into tissues. The advantages of these cells are that they have the ability to move throughout the body and can release their cytokines in the place they are required, which can be used to carry other molecules, including drugs, to tissues affected by diseases or tumors. Currently, there are more than 1000 clinical trials registered at ClinicalTrials.gov that use mesenchymal cells and more than 15 companies with products based on them for clinical treatments. ${ }^{14}$

Evidence suggests that cell therapies have the capability to change the way to confront diseases, including cancer, since for the first time they offer the possibility of cure. There are still numerous obstacles, from obtaining the primary cells, industrial manufacture of the cell products, their distribution and cost, to clinical complications and side effects that have not yet been anticipated; however, everything seems to indicate that they are the future of medicine.

\section{References}

1. Horwitz ME, Chao NJ, Rizzieri DA, Long GD, Sullivan KM, Gasparetto C, et al. Umbilical cord blood expansion with nicotinamide provides longterm multilineage engraftment. J Clin Invest. 2014;124(7):3121-3128

2. Horwitz ME, Cilloni D, Valcarcel D, Frassoni F, Boelens JJ, Jagasia M, et al. Nicord single unit expanded umbilical cord blood transplantation (UCBT): final results of a multicenter phase I/II trial. Blood. 2017;130 Suppl 1:847. 
3. Wagner JE, Brunstein CG, DeFor TE, Boitano AE, McKenna D, Sumstad D, et al. Phase 2 trials with Mgta-456, single cord blood units (CBU) expanded with an aryl hydrocarbon receptor (AHR) antagonist, demonstrate uniform engraftment and rapid hematopoietic recovery in patients following myeloablative or non-myeloablative conditioning. Blood. 2017;130 Suppl 1:662.

4. Wagner JE, Brunstein CG, Boitano AE, DeFor TE, McKenna D, Sums$\operatorname{tad} \mathrm{D}$, et al. Phase $1 / / \mathrm{l}$ trial of stemregenin-1 expanded umbilical cord blood hematopoietic stem cells supports testing as a stand-alone graft. Cell Stem Cell. 2016;18(1):144-155.

5. Fares I, Chagaroui J, Gareau Y, Gingras S, Mayotte N, Csaszar E, et al. Pyrimidoindole derivatives are agonists of human hematopoietic stem cell self-renewal. Science 2014:345(6203):1509-1512.

6. Cohen S, Roy J, Lachance S, Marinier A, Roy DC, Delisle JS, et al. Single UM171 expanded cord blood transplant is feasible, safe, and permits transplantation of better HLA matched cords with very low transplant related mortality. Blood. 2017;130:658.

7. Delaney C, Heimfeld S, Brashem-Stein C, Voorhies H, Manger RL, Bernstein ID, et al. Notch-mediated expansion of human cord blood progenito cells capable of rapid myeloid reconstitution. Nat Med. 2010;16(2):232-236.

8. Delaney C, Milano F, Cicconi L, Othus M, Becker PS, Sandhu V, et al. Infusion of a non-HLA-matched ex-vivo expanded cord blood progenitor cell product after intensive acute myeloid leukaemia chemotherapy: a phase 1 trial. Lancet Haematol. 2016;3(7):e330-e339.

9. Kalos M, Levine BL, Porter DL, Katz S, Grupp SA, Bagg A, et al. T cells with chimeric antigen receptors have potent antitumor effects and can establish memory in patients with advanced leukemia. Sci Transl Med. 2011;3:95ra73-95ra73.

10. Maude SL, Laetsch TW, Buechner J, Rives S, Boyer M, Bittencourt H, et al. Tisagenlecleucel in children and young adults with B-cell lymphoblastic leukemia. Sci Transl Med. 2011;3(95):95ra73.

11. Neelapu SS, Locke FL, Bartlett NL, Lekakis LJ, Miklos DB, Jacobson CA, et al. Axicabtagene ciloleucel CAR T-Cell therapy in refractory large b-cell lymphoma. N Engl J Med. 2017;377(26):2531-2544.

12. Veluchamy JP, Kok N, van der Vliet HJ, Verheul HMW, de Gruijl TD, Spanholtz J, et al. The rise of allogeneic natural killer cells as a platform for cancer immunotherapy: recent innovations and future developments. Front Immunol. 2017:8:631.

13. Rezvani K, Rouce R, Liu E, Shpall E. Engineering natural killer cells for cancer immunotherapy. Mol Ther. 2017:25(8):1769-1781.

14. Squillaro T, Peluso G, Galderisi U. Clinical trials with mesenchymal stem cells: an update. Cell Transplant. 2016;25(5):829-848. 